\title{
Sleep, Subcortical Stimulation and Kindling in the Cat
}

\author{
T. TANAKA, H. LANGE AND R. NAQUET
}

SUMMARY: A longitudinal study of the effects of sleep on amygdaloid kindling showed that kindling disrupted normal sleep patterns by reducing REM sleep and increasing awake time. Few interictal spike discharges were observed during the awake stage, while a marked increase in discharge was observed during the light and deep sleep stages. No discharges were observed during $R E M$ sleep. During the immediate post-stimulation period the nonstimulated amygdala showed a much higher rate of spike discharge. On the other hand, there was an increase in spike discharge in the stimulated amygdala during natural sleep without preceding amygdaloid stimulation. Amygdaloid stimulation at the generalized seizure threshold during each sleep stage resulted in a generalized convulsion.

The influence of subcortical electrical stimulation on kindled amygdaloid convulsions was investigated in a second experiment. Stimulation of the centre median and the caudate nucleus was without effect on kindled convulsions, while stimulation of the mesencephalic reticular formation at high frequency $(300 \mathrm{~Hz})$ reduced the latency of onset of kindled generalized convulsions. Stimulation of the nucleus ventralis lateralis of the thalamus at low frequency 10 $\mathrm{Hz}$ ) prolonged the convalsion latency, and at high current levels blocked the induced convulsion. Stimulation in the central gray matter at low frequency 10 $\mathrm{Hz}$ ) also blocked kindled amygdaloid convulsions.

RÉSUMÉ: La description, l'organisation et la dissémination des pointes interictales furent étudiées en relation avec les différents stages du "kindling" et par rapport à l'état de vigilance. Dans une deuxième partie de l'étude, les effets de la stimulation de certaines structures sous-corticales avant, pendant ou après "kindling" furent investiguées.

\section{INTRODUCTION}

In 1969, Goddard, McIntyre and Leech demonstrated that daily, brief electrical stimulation of limbic structures eventually resulted in generalized convulsions. This phenomenon, termed kindling, has been largely accepted as a new model of epilepsy, but its mechanism remains to be elucidated.

The purpose of the present experiments is to study the relationship between sleep and the kindling effect, and the possible modification of this phenomenon by electrical stimulation of different subcortical structures.

\section{Experiment 1. Sleep and the \\ kindling effect:}

An intimate relationship between sleep and certain manifestations of epilepsy has been reported by a number of authors (Batini et al., 1962; Gastaut et al., 1965; Gibbs and Gibbs, 1946; Janz, 1962). Consequently, we began an investigation of the relationship between sleep and the kindling phenomenon. Our study was aimed at examining the following: the influence of kindling on sleep organization, the influence of sleep on spiking activity, and the influence of threshold stimulation on the various stages of sleep.

From the Centre National de la Recherche Scientifique. Gif-Sur-Yvette, France.

Reprint requests to Dr. T. Tanaka, c/o Dr. Robert Naquet, Director, Laboratoire de Physiologie Nerveuse, Centre National de la Recherche Scientifique, 91190 Gif-sur-Yvette, France.

\section{METHOD}

Twelve cats of both sexes, weighing between $2.5-4.0 \mathrm{~kg}$ were used. The animals were anesthetized with pentobarbital $(30 \mathrm{mg} / \mathrm{kg}$, i.p.), and stainless steel screws were implanted on the skull under aseptic conditions for cortical and electro-oculogram recordings. Concentric depth electrodes were constructed of $0.4 \mathrm{~mm}$ stainless steel tubing with a central $0.2 \mathrm{~mm}$ stainless steel wire, and insulated with Epoxylite except for 0.5 $\mathrm{mm}$ at the tip. Electrodes were stereotaxically implanted into the following structures using the stereotaxic atlas of Jasper and Ajmone-Marsan (1954): basolateral amygdala bilaterally (AMG), left ventral hippocampus (HIPP), left ventralis lateralis (VL) and centre median (CM) of the thalamus, left mesencephalic reticular formation (MRF), and left caudate nucleus (CN). Teflon coated stainless steel wires were placed in the posterior neck muscle and subcutaneous thoracic region for electromyogram and electrocardiogram recordings, respectively.

Following the operation, chloramphenicol $(1.0 \mathrm{~g} /$ day, s.c.) was administered for 3 days. The animals were allowed to recover for at least 10 days. The techniques and conditions for the electrographic recordings were similar to those reported previously (Tanaka and Naquet, 1975). Animals were fed at about 8:30 a.m. and placed in soundproofed recording chambers $(100 \times 80 \times$ $80 \mathrm{~cm}$ ) at about 10:00 a.m. until 4:00 p.m. The animals were placed in the recording chamber for several days without recording. After this habituation period, control electrographic recordings were taken for 3 days to verify the sleep organization of the animals. All recordings were made at a speed of 15 $\mathrm{mm} / \mathrm{sec}$. The state of vigilance was classified into four stages: awake (AWA), light slow wave sleep (LSW), deep slow wave sleep (DSW), and rapid eye movement sleep (REM).

The animals were separated into two groups: Group A, the control group (four animals), and Group B, the kindled group (eight animals). For Group A, control electrographic recordings were made 


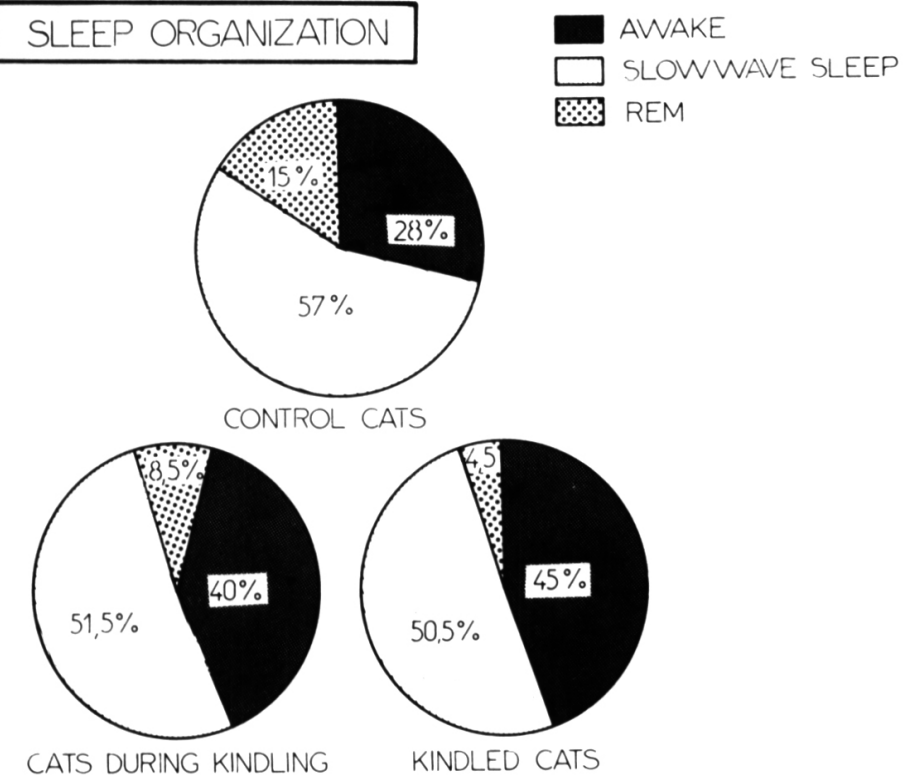

Figure 1-Sleep organization of control animals (Group A) $(\mathrm{N}=20)$; and during kindling (Group $\mathrm{B})(\mathrm{N}=46)$ and after kindling (Group $B)(N=28)$. Note the remarkable reduction in REM sleep after kindling has been established.
TABLE 1

Typical interictal spike propagation during each stage of vigilance by day.

\begin{tabular}{|l|c|c|c|c|c|}
\hline & & AWA & LSW & DSW & REM \\
\hline MCx L & & 10 & 7 & 6 & - \\
\hline McxR & & 10 & 7 & 6 & - \\
\hline Anl.Temp L & & 9 & 6 & 6 & - \\
\hline AMG L & $※$ & 3 & 1 & 1 & - \\
\hline AMG R & & 5 & 2 & 2 & - \\
\hline Hipp L & & 3 & 2 & 2 & - \\
\hline VL L & & 6 & 4 & 4 & - \\
\hline CM L & & 4 & 4 & 3 & - \\
\hline MRF L & & 11 & 8 & 8 & - \\
\hline Caud NI & & 5 & 5 & 5 & - \\
\hline
\end{tabular}

irregularly as described above for about 1 year (range: 9 to 13 months). Group B animals were kindled by daily electrical stimulation of the amygdala (for details see Tanaka and Lange, 1975. Tanaka and Naquet, 1975), and were followed for about 1 year (range: 10 to 13 months). Stimulation (biphasic square waves 1.0 msec. in duration, at $62.5 \mathrm{~Hz}$ and 100 to $300 \mu$ a intensity, of $2 \mathrm{sec}$. duration) was applied during the resting awake stage at about 11:00 a.m. Daily electrical stimulation and recording continued until the kindling effect was established (Goddard et al., 1969; Wada and Sato, 1974). Once kindling was established, the threshold stimulation intensity required to provoke a generalized convulsion was determined (Tanaka and Naquet. 1975; Wada and Sato, 1974). Electrographic recordings were made as described for Group A. Occasionally, 24 hour recordings were also made.

Beginning $10 \mathrm{~min}$. after each amygdaloid stimulation spike frequency was recorded for 5 hrs. The definition of a spike for the purposes of this study is spike-like activity of a duration no greater than $80 \mathrm{msec}$, and amplitude greater than $150 \mu \mathrm{v}$ peak to peak. All artifacts resulting from ocular movement, muscle twitching and body movements were eliminated by examination of concurrent electromyogram and electrocardiogram recording. Spikes recorded during the different stages of vigilance were treated statistically. Spikes occurring during DSW were analyzed with an Intertech- nique computer, and a harmonic analysis by Fourier transform was carried out.

At the end of the experiment, the animals were perfused with normal saline and $10 \%$ formalin solution under pentobarbital anesthesia. Frozen sections were taken every $100 \mu$ and stained by

\section{- CAT GT 23}

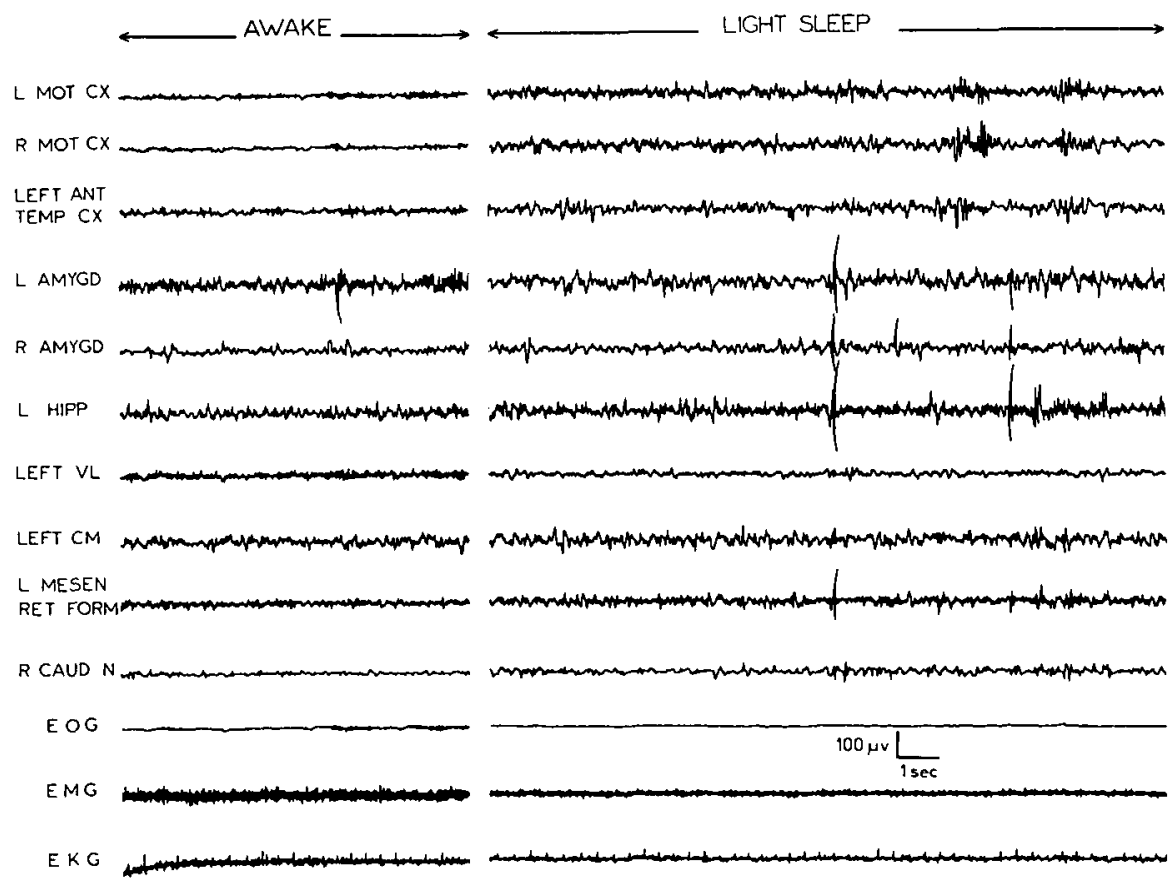

Figure 2-Electrographic recording from kindled cat during wakefulness and LSW sleep. 
recording. All Group A animals showed stable electrographic sleep organization throughout the experimental period. During the monitored time period (11:00 a.m. to 4:00 p.m.) they had a high sleep ratio, as shown in Fig. 1 (Angeleri et al., 1969; Delorme et al., 1964; Jouvet, 1965; Lanoir, 1972).

All Group B animals were kindled within approximately 20 days (range: 17 to 25 days). Arousal patterns and localized after-discharges were observed initially, followed by a progressive increase of waking time (Fig. 1). When kindling was completed, a generalized tonic-clonic convulsion was preceded by a localized amygdaloid after-discharge. The amount, frequency and duration of the REM component decreased remarkably during the recording sessions as kindling progressed. The AWA stage was moderately prolonged, but slow wave sleep was little influenced. No rebound increase of REM was observed during $24 \mathrm{hr}$. monitoring. Although a slight increase of REM was noticed during the night, the amount of REM over $24 \mathrm{hrs}$. remained less than that of the control animals.

Influence of the sleep-wakefulness cycle on interictal spike discharge:

No spike activity was observed in the Group $A$ animals during the experimental period. A small amount of spike-like activity was observed in the AMG and HIPP during the SWS stage, but the configuration and pattern did not meet the criteria for spikes described previously.

In the Group B animals spike, polyspike or spike and wave activity was recorded during all states of vigilance except REM. The morphology of the spike was not modified by arousal or slow wave stages (Fig. 2 and 3). During kindling a remarkable increase in spike frequency was observed, and was most pronounced in the LSW and DSW stages, in contrast to the slight increase during the AWA stage (Figs. 4 and 5). Spiking during the AWA stage gradually diminished before the completion of kindling. During seizure development there was an appreciable increase in spike frequency in the

\section{- CAT GT 23}

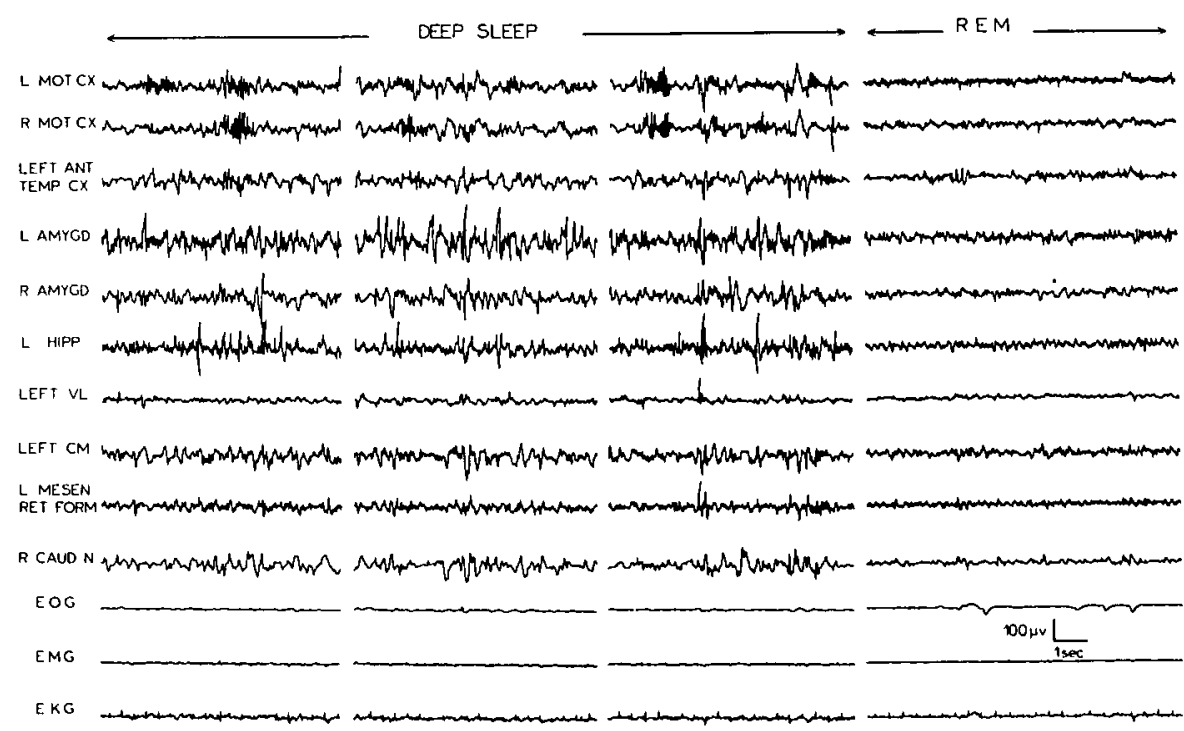

Figure 3-Electrographic recording from kindled cat during DSW and REM sleep.

LSW and DSW stages, which reached its peak between the 12th and 17 th day. Two or 3 days before the completion of kindling, a remarkable reduction in spike frequency was noted; this was followed by a moderate increase which persisted. The nonstimulated AMG showed the highest spike frequency in both slow wave stages during the experimental period. No spike activity was observed during the REM stage. Once kindling was completed spike frequency diminished drastically during the AWA stage (Wada and Sato, 1974); however, spiking was still frequent during the LSW and DSW stages. This spiking activity persisted longer than one year after the first stimulation. No spike activity was observed during the REM stage in this period.

The typical order of appearance of interictal spike discharge each day is shown in Table 1. Discharges first appeared at the stimulated AMG,

Figure 4-Histograms showing average interictal spike frequency of all the structures recorded. Note remarkable decrease in interictal spike frequency in the awake stage after kindling.

$$
\begin{aligned}
& \text { spike activity and sleep-wakefulness } \\
& \text { cycle during five hour recording. }
\end{aligned}
$$

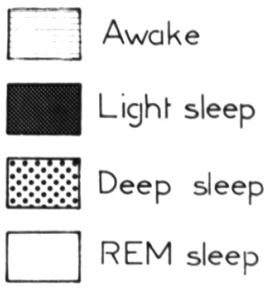

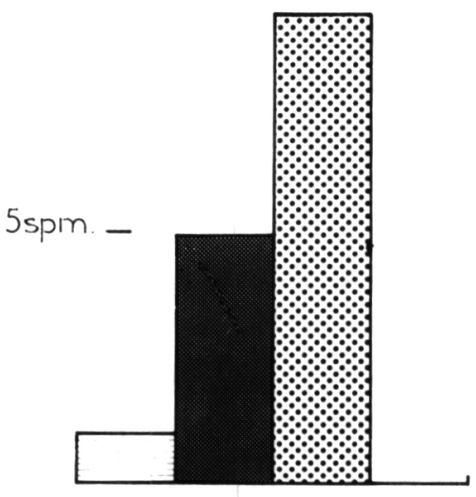

during kindling installation

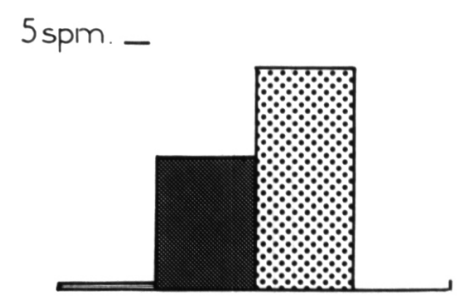

affer kinclling has been established 
followed by appearance at the contralateral AMG and the HIPP, VL, $\mathrm{CM}, \mathrm{CN}$, ipsilateral anterior temporal cortex, bilateral motor cortex, and MRF in that order.

Kindled animals were left for at least 7 days without amygdaloid stimulation. Subsequent recordings made during the various stages of sleep showed few spikes during the AWA stage and no spikes during the
REM stage. During the LSW and DSW stages the stimulated AMG showed a greater spike frequency, and the contralateral AMG showed a lesser spike frequency than that during the immediately post-stimulated state.

Spikes occurring during DSW were counted and analyzed by Fourier transform. This particular stage was chosen for this analysis
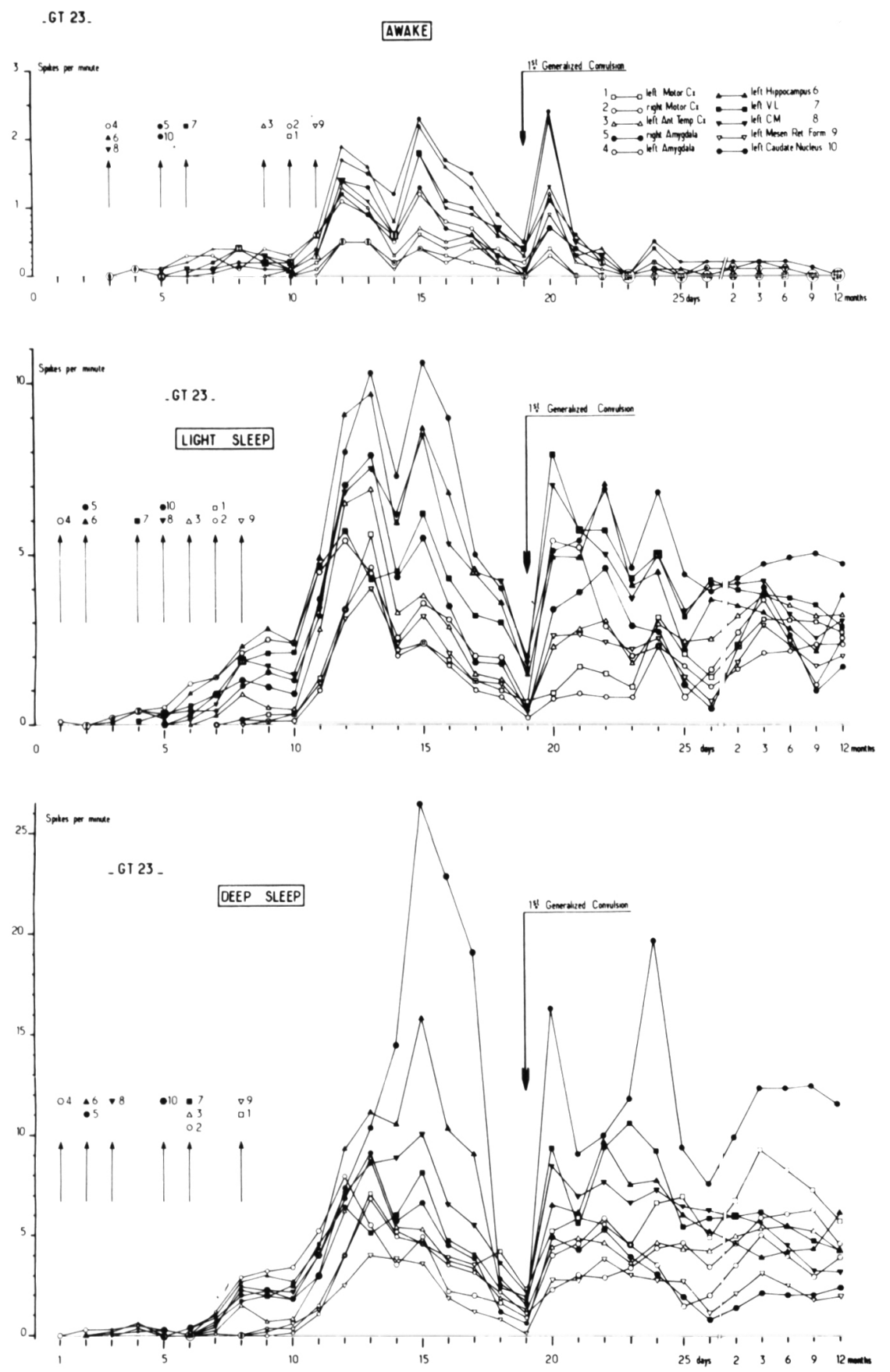

Figure 5-Chronology of interictal spike activity in different cortical and subcortical structures of a Group B cat during the sleep-wakefulness cycle.

because spiking activity was most frequent, and the frequency and duration of DSW episodes were stable (Tanaka and Naquet, 1975). The analysis revealed a periodicity of spike generation in both stimulated and contralateral AMG, HIPP, VL, $\mathrm{CM}$, and MRF throughout the kindling process. The contralateral AMG showed two types of periodicity, one of the same period as the stimulated $A M G$, and one with much shorter periods (Lange et al., 1975).

After the completion of the kindling process, the threshold stimulation intensity necessary to evoke a generalized convulsion was determined. This was found to be considerably lower than the initial intensity required to evoke afterdischarge and partial seizures (McIntyre and Goddard, 1973; Racine, 1971; Wada and Sato, 1974). Stimulation applied during the LSW, DSW, and REM stages at threshold intensity in all instances produced electroclinical evidence of arousal, followed by a generalized tonic-clonic convulsion.

\section{DISCUSSION}

The findings described here confirm those of previous workers (Goddard et al., 1969; Wada and Sato, 1974); daily electrical stimulation of the amygdala eventually results in generalized convulsions. The effect of kindling on the sleepwakefulness cycle was to diminish the duration of the REM stage and to increase the duration of the AWA stage. In the present study slow wave sleep (particularly DSW, but not REM) facilitated interictal discharges. This finding is consistent with previous reports (Batini et al., 1962; Gastaut et al., 1965; Gibbs and Gibbs, 1946; Janz, 1962).

Wada and Sato (1974) reported a progressive increase in interictal discharge frequency during the latter half of the kindling process in cats, with an abrupt decrease after the completion of kindling. Our results confirm this finding for the AWA stage. However, during the LSW and DSW stages spiking increases rapidly during the early stages of kindling, is reduced at the time of the first generalized convulsion, and increases again after the development 
of generalized convulsions, persisting thereafter.

REM sleep has been reported to activate (Delange et al., 1962; Gastaut et al., 1965; Passouant et al., 1965) or suppress (Kikuchi, 1969) spiking in some patients with temporal lobe epilepsy. Consistent with our findings, spiking was not observed during REM in monkeys with a cobalt amygdaloid focus (Mayanagi and Walker, 1974). The absence of spiking during REM may have the same basis as the diminution of spiking during the AWA stage following the completion of kindling. Judging from the pattern of hippocampal theta activity, the intensity or degree of activation during the REM stage may be stronger than during the AWA stage.

Spike activity was observed at the stimulated AMG during LSW and DSW following the first electrical stimulation, even if the stimulation intensity was below the afterdischarge threshold. This finding suggests that amygdaloid mechanisms may be modified by the first subthreshold stimulation.

We observed rapid propagation of interictal spike activity in the contralateral AMG, the structure that always showed the most frequent spiking activity, in contrast to moderate rates of interictal spiking at the stimulated site. A similar finding has been reported in the amygdaloid kindling of Senegalese baboons (Wada and Osawa, 1974). Spiking was most frequent in the contralateral AMG after a period without stimulation; however, at this time spiking in this site was reduced to levels below that of the stimulated site. This suggests that the excitability of the stimulated AMG was reduced after the development of generalized convulsions. In contrast, the excitability of the contralateral AMG must have been raised by the electrical stimulation. A Fourier analysis of the spiking showed an independent oscillation with a rapid cycling in the contralateral AMG. This suggests that the kindling phenomenon is one of the best models of the distant epile togenic focus (Morrell, 1973).
Experiment 2. Modification of kindled convulsions by stimulation of subcortical structures:

In 1974 Wada and Sato reported that once the kindling effect had been obtained by amygdaloid stimulation in cats, threshold stimulation always provoked amygdaloid afterdischarge followed by a generalized convulsion. However, if the animals were stimulated below the critical threshold there was no electroclinical ictal response (an "all or none" phenomenon). With this in mind we examined the effect of stimulation of various subcortical structures on kindled amygdaloid convulsions.

\section{METHOD}

Nine cats weighing between $2.5-3.5 \mathrm{~kg}$ were used. Surgical techniques are detailed elsewhere (Tanaka and Naquet, 1975). Stimulating and recording electrodes were implanted unilaterally in the left AMG, VL, CM, CN, MRF, and central gray matter (CGM). The stereotaxic atlas of Snider and Neimer (1961) was used to obtain coordinates for the last structure. Daily amygdaloid stimulation was administered until the appearance of a generalized convulsion, after which seven additional convulsions were produced at reduced current intensities ranging between $20-50 \mu \mathrm{a}$. If no convulsion was triggered at the initial reduced current level of 20 a, 10 a was added to this current level the next day. When the generalized seizure triggering threshold (GST) had been determined by this method (Wada and Sato, 1974), its stability was examined for 3 days. (Fig. 6). The GST thus established had the following characteristics: The intensity varied between 80-150 $\mu \mathrm{a}$, and duration varied between 1-2 sec., depending on the animal. The pulse duration and frequency of the biphasic, square wave stimulation were fixed at $1.0 \mathrm{msec}$. and $62.5 \mathrm{~Hz}$, respectively.

Stimulation of other subcortical structures was by 3 Tektronix stimulators and was monitored with an oscilloscope. Biphasic square wave stimulation was delivered to subcortical structures at the following parameters: pulse duration, 0.3 msec., frequency between $10-300 \mathrm{~Hz}$, intensity $100-300 \mu$ a and duration $60-3600$ sec. Subcortical stimulation was applied before amygdaloid stimulation, and at times continued during and irregularly after amygdaloid stimulation: Clinical manifestations of subcortical stimulations were weak except for high frequency stimulation of MRF (strong arousal) and low frequency stimulation of CGM (tranquilization).

Electrode positions were verified in the same manner as in Experiment 1. The kindling electrodes were in the basolateral amygdala, and the other electrodes were in the intended structures.

\section{RESULTS}

The latency from the end of amygdaloid stimulation to the commencement of the generalized con-

\section{- Diminution of Threshold after each Convulsion -}

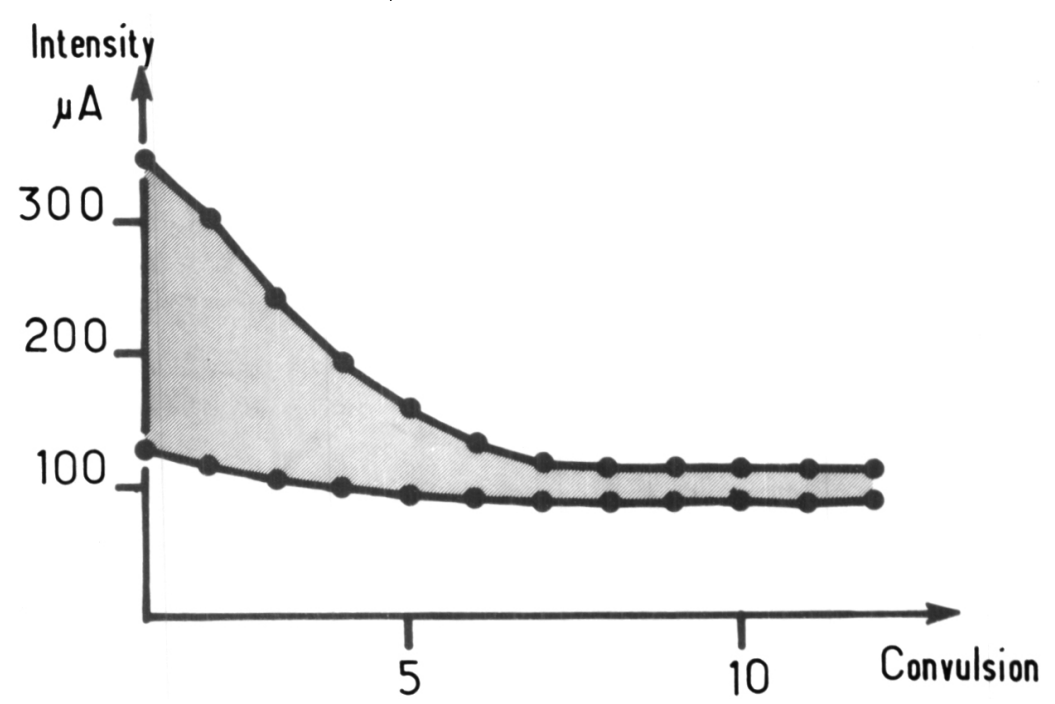

Figure 6-Diminution of threshold after each convulsion. The days in which no convulsion was triggered were omitted. 
vulsion (GCL) induced by stimulation at the GST was found to be between $26-35$ sec. (mean $30.5 \mathrm{sec}$.) (Fig. 7).

No significant modification of the GCL was observed with stimulation of $\mathrm{CM}$ and $\mathrm{CN}$ at any parameter, and with MRF stimulation between frequencies of 10-62.5 Hz. Stimulation at $300 \mathrm{~Hz}$ produced a shortening of the GCL to $16-25 \mathrm{sec}$. (mean 20.0 sec.) (Fig. 8). Little effect of VL stimulation was obtained with stimulation at $60-300 \mathrm{~Hz}$. However, stimulation of $\mathrm{VL}$ at $10 \mathrm{~Hz}$ and intensities between 100-200 $\mu$ a prolonged the GCL to $30-62 \mathrm{sec}$. (mean $50.0 \mathrm{sec}$.). Stimulation at intensities above 300 $\mu$ a blocked the amygdaloid-induced generalized convulsion in spite of the fact that electrographic afterdischarge was triggered and propagated into subcortical and cortical structures (Fig. 9). When VL stimulation was continued after the amygdaloid stimulation, complete blockage of afterdischarge often occurred (Fig. 10 ). When the AMG was stimulated with a current $50 \mu$ a greater than the GST, stimulation of VL became ineffective in blocking the generalized convulsion in all cases. Stimulation of CGM at $10 \mathrm{~Hz}$ with $200 \mu$ a for longer than $360 \mathrm{sec}$. completely blocked the kindled convulsions, and all afterdischarge. When the AMG was stimulated with a current $50 \mu$ a greater than the GST the CGM effect was no longer present, even with CGM stimulation continued as long as $3600 \mathrm{sec}$. before AMG stimulation.

\section{DISCUSSION}

The results of this experiment demonstrate that kindled AMG convulsions can be modified by stimulation of certain subcortical structures such as the MRF, VL and CGM. With respect to the MRF it has been reported that MRF stimulation either blocked or activated generalized seizures (Babb et al., 1974; Lairy-Bounes et al., 1952; Naquet et al., 1956; Testa and Gloor, 1974). Our results showed that high frequency MRF stimulation that produced an arousal reaction reduced the latency to generalized

\section{CAT GT.63 CONTROL}

03.02 .75
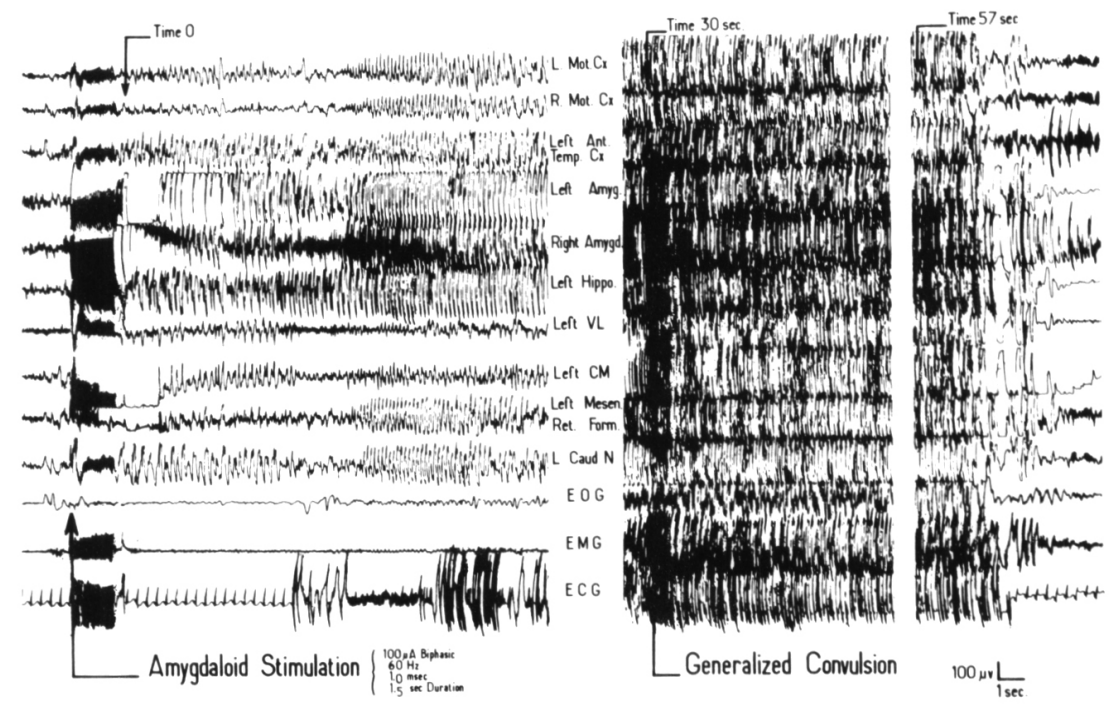

Figure 7-Generalized convulsion with threshold stimulation.

convulsions produced by amygdaloid stimulation.

With respect to the VL, Babb et al. (1974) reported facilitatory and inhibitory effects of VL stimulation at different parameters in cobaltinduced hippocampal epilepsy. It is well known that stimulation of the cerebellum in animals (Dauth et al., 1974; Dow et al., 1962; Iwata and Snider, 1959; Snider, 1974) and in humans (Cooper and Gilman, 1973) produces an inhibitory effect on certain epileptic manifestations. How- ever, Wada (1974) has found cerebellar stimulation to be non-effective against kindled AMG convulsions in the baboon, Papio papio, and against seizure development in the rhesus monkey, with some acceleration of seizure development in the latter. Our results suggest that VL stimulation may activate some cerebellar inhibitory circuits, since the VL is a relay nucleus between the cerebellum and the motor cortex. It is interesting that VL stimulation blocked the clinical expression of
CAT GT.63

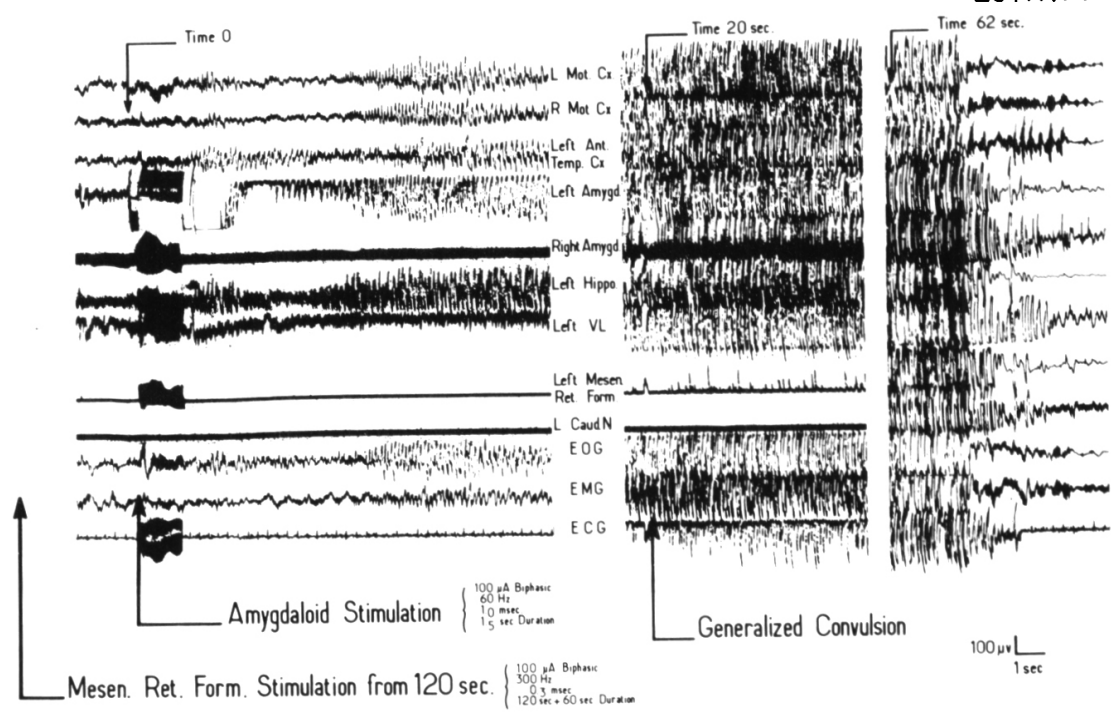

Figure 8-Stimulation of MRF. Note shortening of latency from stimulation of amygdala to beginning of generalized convulsion. 


\section{CAT GT. 51}

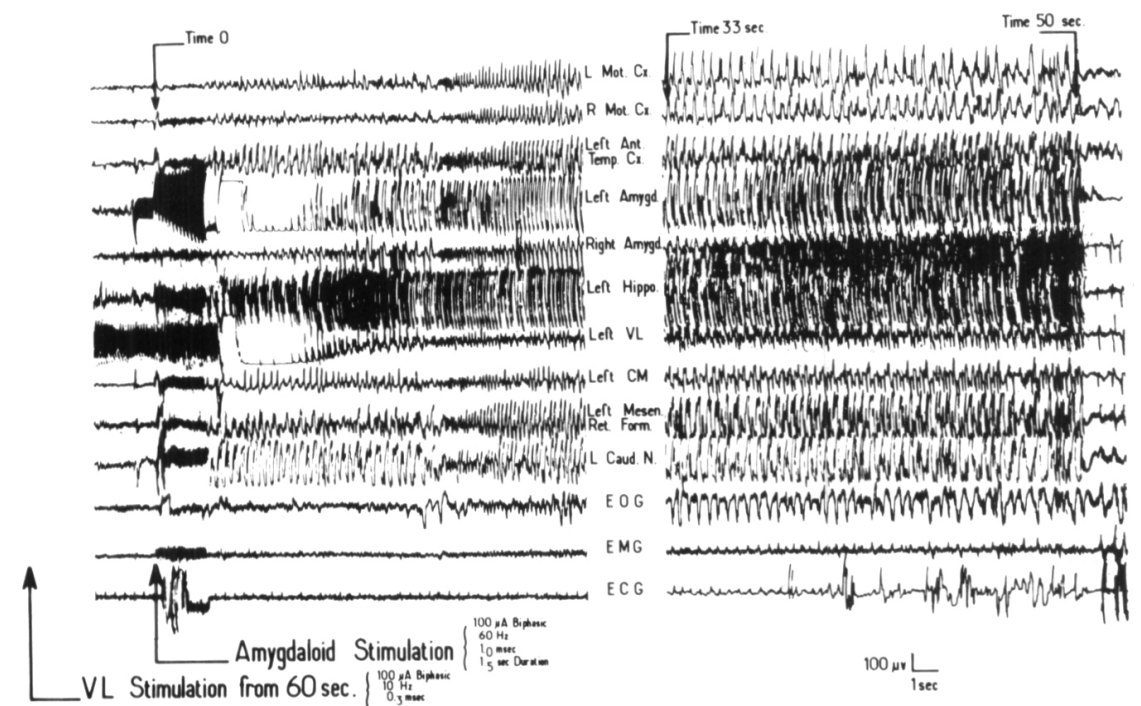

Figure 9-Inhibition of generalized convulsion by VL stimulation with low frequency $(10 \mathrm{c} / \mathrm{s})$. generalized convulsions, and not the evoked afterdischarge.

Regarding CGM stimulation, there is evidence that such stimulation may inhibit pain (Oliveras et al.,
1974). Jasper (personal communication, 1975) demonstrated that low frequency CGM stimulation $(10 \mathrm{~Hz})$ produced a remarkable increase of GABA in the cortical perfusate. In

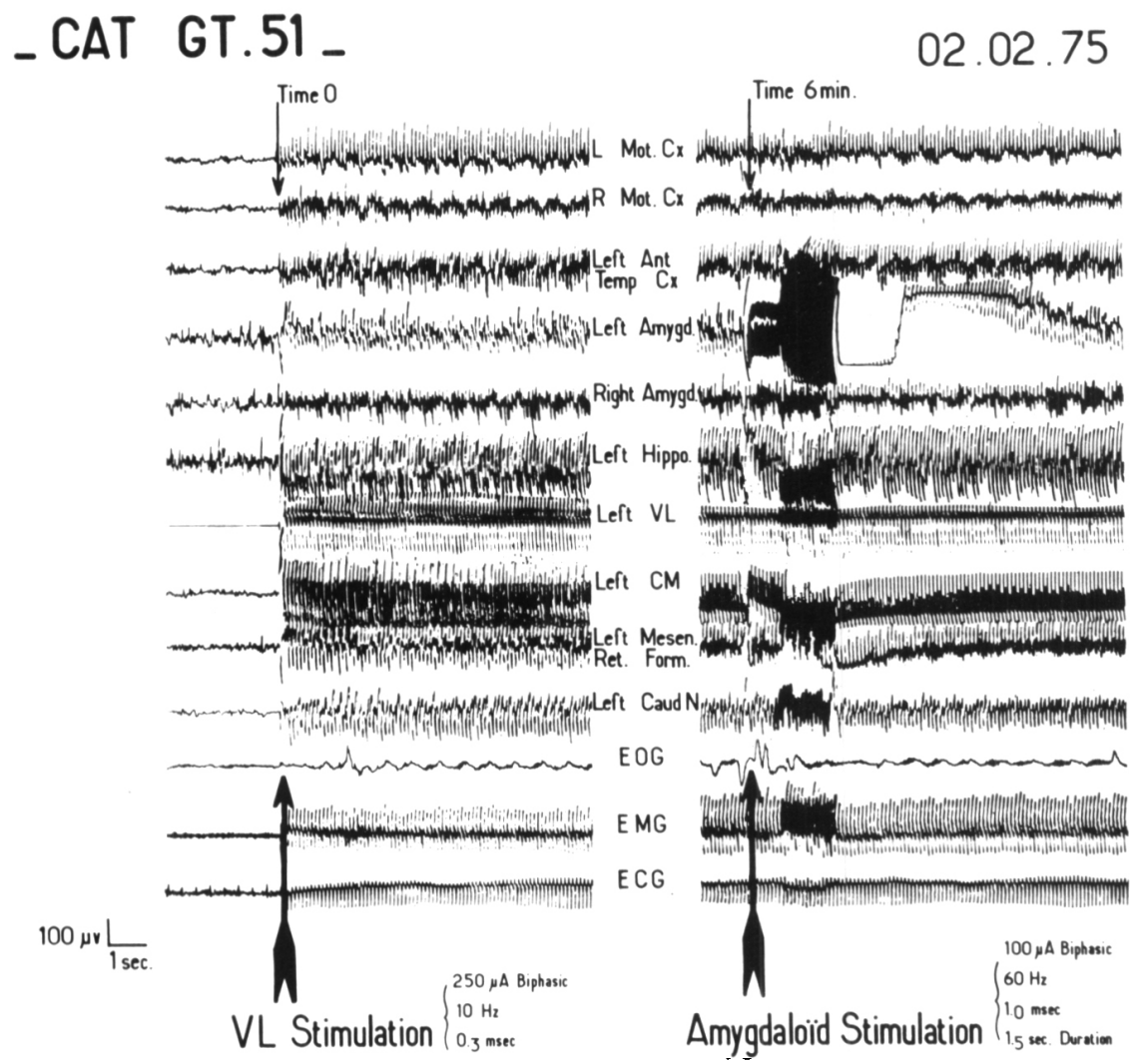

Figure 10-Complete blockage of amygdaloid threshold kindling stimulation by VL stimulation at an elevated intensity. the present study CGM stimulation may have blocked all electroclinical expression of kindled AMG seizures by a mechanism involving an increase of GABA in the cortex. It is well known that administration of dipropyl acetate (DPA) increases the quantity of GABA in the brain (Godin et al., 1969). Tanaka and Lange (1975) reported that complete inhibition of the kindled convulsion resulted when more than $300 \mathrm{mg} / \mathrm{kg}$ DPA was administered intraperitoneally $15 \mathrm{~min}$. before AMG stimulation in rats. Moreover, 100 $\mathrm{mg} / \mathrm{kg}$ DPA administered intraperitoneally before every AMG stimulation blocked the development of seizures by kindling.

In the future it would be interesting to investigate the inhibitory mechanisms of VL and CGM stimulation and the facilitatory mechanism of MRF stimulation by means of a neuropharmacological approach.

\section{GENERAL DISCUSSION}

The kindling model of epilepsy used in this study has demonstrated its usefulness for an understanding of epilepsy in man (Purpura et al., 1969). Other syndromes such as audiogenic seizure susceptibility or the photosensitivity of the baboon, Papio papio, give information about the genetic origin of epilepsy (Balzamo et al., 1975; Naquet, 1975). Cobalt or alumina cream-induced epilepsy provide information on focal epilepsy and the propagation of seizure activity. Metrazol activation yields information on the origin of

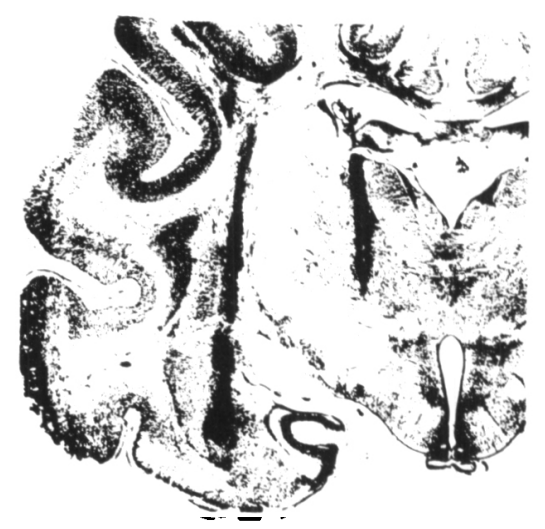

Figure 1/-Electrode placement of kindled amygdala and stimulated VL. 
the so-called "centrencephalic seizure" or generalized seizure (Fischer-Williams et al., 1968; Killam et al., 1967).

The kindling model has different properties, and enables us to study, for example, interictal discharge propagation and the "all or none" quality of the kindled generalized convulsion (Wada and Sato, 1974).

Our contribution to this symposium points out the relationship between the stages of sleep and the various electroclinical manifestations of kindled seizures, and demonstrates a modulating role of certain subcortical structures on kindled seizures. However, clarification of the full significance of these results must await further work.

\section{DISCUSSION}

Dr. McIntyre: I would like to congratulate Dr. Tanaka and his colleagues on some very elegant papers. Did you notice any behavioral change in the cat that exhibited less REM sleep? You say there was no REM rebound also; was there a rebound of spikes? If there wasn't, do you think that perhaps the lack of a REM rebound phenomenon might be explained as if the spikes themselves substitute for whatever physiological role REM sleep performs? Dr. Tanaka: That is a very interesting question. On the point of behavior after kindling, the cats were more irritable than normal cats. We observed every day that when we transported the cats from cage to the observation recording chamber, the kindled cats were more irritable than the normal cats. We have not observed a rebound of spike discharges. By my present study I cannot say if there is or not. Dr. Wada: The last point Dr. McIntyre raises is, I think, quite relevant in view of Dr. Stevens" concept of "obligatory discharge" and "spike pressure". Dr. McIntyre: Your description of "all or none" responses in the kindled animals is generally true but not universal. Both Racine and myself (with Morrell) have seen abortive seizures sometimes triggered by threshold stimulation. Dr. Wada: I think that it should be stressed that "all or none" is probably a relative phenomenon but it is certainly very easy to demonstrate in amygdaloid kindling in both cats and baboons but rather difficult to establish from prefrontal cortical sites in these species. This finding suggests to me that the establishment of a generalized seizure triggering threshold in our animals depends upon the powerful subcortical connections which the amygdala has. I would imagine one would experience a similar difficulty if kindling was established from the posterior cortical site. Dr. Morrell: Your finding of reduced norepinephrine and dopamine in kindled brains suggest that my fear of cycloheximide result being due to reduced catecholamine is unfounded - the effect is opposite to that you would expect. My question is how do you know your finding is not related to the hyperactivity rather than causative? Dr. Tanaka: It is difficult to know at this point. Dr. Cain: I believe you have administered electrical stimulation of the MRF and other loci concurrent with amygdaloid stimulation in fully kindled animals We are just about to start these experiments in the kindling preparation. The effects may be quite different in each case; that is, the kindled, and presumably reorganized brain, may react differently to concurrent stimulation compared with the kindling, but not yet reorganized brain. Dr. Tanaka: We have not experimented during the kindling procedure yet. Dr. McIntyre: Was the caudate one of the structures that you stimulated prior to stimulating the amygdala and looking at the inhibitory and facilitory roles and did it have no effect? Dr. Tanaka: Yes, the caudate was one of the structures and there was no effect. Dr. McIntyre: I believe that there was an Italian group that reported very dramatic inhibitory effects of antecedent caudate stimulation on the amygdala and I happen to have done the experiment referred to a minute ago with rats trying to see if it held true and nothing happens at all. It was during the kindling process to see if it would influence any of the aspects of kindling and it did nothing at any level. Dr. Tanaka: How high a frequency did you use in the caudate? Dr. McIntyre: The intensity I believe was $150 \mathrm{~Hz}$ to the caudate, $50 \mu$ \& to the amygdala. The duration was 5 sec to the caudate and $5 \mathrm{sec}$ to the amygdala. The caudate kindled very nicely. I was fascinated by your data with the central gray and the VL. These data seem to fit very nicely with all the things that we've been talking about in terms of tetanic stimulation because if you look at the tetanic stimulation that is administered has the facilitory effects of the reticular activation which is a tetanic response, and the low frequency which doesn't kindle anything, is inhibitory in all the mechanisms. Dr. Wada: Dr. Stevens has done quite a bit of observation on caudate stimulation and I would like to ask her to comment on this topic. Dr. Stevens: I rise to defend the caudate nucleus. I was at a meeting just about ten days ago in Bratislava where the Russians are using caudate stimulations specifically to arrest seizures commencing in the amygdala. Actually, in man, they have electrodes; they're not kindling of course, they're not kindling the amygdala. I think that they may be kindling the caudate or kidding the rest of us, but what they did find that $I$ think is important for your beautiful studies and those of you who are shopping in the caudate for an inhibitory site, is that it was very important to go point by point through the caudate and not treat it as a homogeneous structure. As you know, it has a topographical projection on it from the cortex and they found as they were simultaneously recording both with gross electrodes and microelectrodes in the amygdala from an epileptic focus made by God, that there were points in the caudate that would stop the seizure discharge and other points in the caudate that would make it worse and that only if they gave their daily stimulation at the inhibitory parts of the caudate nucleus did they get lasting effect on seizures. The other thing that I want to mention while I've got the microphone is that the VL in addition to its cortical connection is the major route from caudate to cerebellum so perhaps its greater potency reflects the fact that the caudate's outflow is now coming down and one is stimulating larger portions of it at its outflow. Dr. Tanaka: Thank you very much. I have much appreciated Dr. Stevens' comments. Dr. Ojemann: We started the day discussing kindling as a model of long term memory in man. If the dominant VL is stimulated during input of verbal information, later recall of that information from long term memory is enhanced. That is exactly what one would expect if VL stimulation blocks kindling, which is the engram of long term memory. Dr. Morrell: Did the DPA treatment interfere with the afterdischarge itself from the kindling stimulation? Dr. Tanaka: The effect of DPA when one gives $200 \mathrm{mg}$ resulted in complete inhibition of afterdischarge but if one reduces the quantity of DPA one observes afterdischarge. Dr. Wada: This DPA story is very intriguing in view of our experience with 3-mercaptoproprionic acid in kindling. Obviously we need more work to clarify the GABA story. Dr. Adamec: Could you characterize your electrode placements in the amygdala as falling within a circumscribed nucleus group? Dr. Tanaka: I tried to do only the lateral group but sometimes the electrode tip was found in the basal group. Dr. Adamec: I'm not sure if I understood your figure in regards to your sleep study. I believe that you mentioned there was a gradual increase in the duration of the afterdischarge as the percentage of REM decreased. Did you have to see a significant decrease in the REM? Dr. Tanaka: From the statistical part of this study we found that we cannot say that the specified increase of total afterdischarge corresponds with the reduction of REM sleep. $D r$. Adamec: It is interesting that the result of your mesencephalic reticular stimulation might suggest one route through which your activity is not going and I refer to the studies of Tsubokawa and Sutin who demonstrated that high frequency stimulation in the mesencephalic reticular formation inhibited activity in the ventral medial nucleus of the hypothalamus upon cells which received input from the basal amygdala. Perhaps this might suggest that the facilitation that you get of the mesencephalic stimulation is routing through some area other than through this particular one of the major outflows of the amygdala. Dr. Cain: We are currently examining the effect of concurrent stimulation of the MRF during kindling. Have you done that? Dr. Tanaka: No, we have not done that. Dr. Wada: It should be pointed out that the effect of the drug or lesion, say MRF lesion, can vary considerably depending on whether one uses a kindling process, i.e., developing seizure, or a kindled one, i.e., developed seizure. In our experience, MRF lesion blocks the latter while it has practically no effect upon development of amygdaloid seizure. This is why we are beginning to look at the effect of stimulation as Dr. Cain has just mentioned.

\section{BIBLIOGRAPHY}

ANGELERI, F., MARCHESI, G. F and QUATTRINI, A. (1969). Effects of chronic thalamic lesions on the electrical activity of the neocortex and on sleep. Archives Italiennes de Biologie, 107, 633-667.

BABB, T. L., MITCHELL, A. G., JR. and CRANDALL, P. H. (1974). Fastigio-bulbar and dentatothalamic influences on hippocampal cobalt epilepsy in the cat. Elec- 
troencephalography and Clinicla Neurophysiology, 36, 141-154.

BALZAMO, E., BERT, J., MENINI, C. and NAQUET, R. (1975). Excessive light sensitivity in Papio papio: its variation with age, sex and geographic origin. Epilepsia, 16, 269-276.

BATINI, C., CRITICOS, A., FRESSY, J. and GASTAUT, H. (1962). A propos du sommeil nocturne chez des sujets présentant une épilepsie à expression EEG bisynchrone. Revue Neurologique, (Paris), 106, 221-224.

COOPER, I. S. and GILMAN, S. (1973). The effect of chronic cerebellar stimulation upon epilepsy in man. 98th Annual Meeting, American Neurological Association, July 11-13, Montreal.

DAUTH, G., CARR, D. and GILMAN, S. (1974). Cerebellar cortical stimulation effect on EEG activity and seizure after discharge in anaesthetized cats. In: The Cerebellum. Epilepsy and Behavior. 229-244, Plenum Press, New York.

DELANGE, M., GASTAN, P., CADILHAC, J. and PASSOUANT, P. (1962). Etude du sommeil de nuit au cours d'épilepsies centrencéphaliques et temporales. Revue Neurologique, (Paris), 106, 106-113.

DELORME, F., VIMONT, P. and JOUVET, D. (1964). Etude statistique du cycle veille-sommeil chez le chat. Compte Rendus des Seances de la Societe de Biologie et de Ses Filiales, (Paris), 158, 2128-2130.

DOW, R. S., FERNANDEZ-GUARDIOLA, A. and MANNI, E. (1962). The influence of the cerebellum in experimental epilepsy. Electroencephalography and clinical Neurophysiology, 14, 383-398.

FISCHER-WILLIAMS, M., PONCET, M., RICHE, D. and NAQUET, R. (1968). Light induced epilepsy in the baboon, Papio papio: cortical and depth recordings. Electroencephalography and clinical Neurophysiology, 25, 557-569.

GASTAUT, H., BATINI, C., FRESSY, J. BROUGHTON, R., TASSINARI, C. A. and VITTINI, F. (1965). Etude électroencéphalographique des phénomènes épisodiques au cours du sommeil. In: Sommeil de nuit normal et pathologique. Masson, Paris, 239-254.

GIBBS, E. L. and GIBBS, F. A. (1946). Diagnostic and localizing value of electroencephalographic studies in sleep. Research Publication of the Association for Research in Nervous and Mental Diseases, 26, 366-376.

GODDARD, G. V., McINTYRE, D. C. and LEECH, C. K. (1969). A permanent change in brain function resulting from daily electrical stimulation. Experimental Neurology, 25, 295-330.

GODIN, Y., HEINER, L., MARK, J. and MANDEL, P. (1969). Effect of Di-nPropylacetate, and anticonvulsive compound, on GABA metabolism. Journal of Neurochemistry, 16, 869-873.

IWATA, M. and SNIDER, R. S. (1959).
Cerebello-hippocampal influences on the electroencephalogram. Electroencephalography and clinical Neurophysiology, 11, 439-446.

JANZ, D. (1962). The grand mal epilepsies and the sleeping-waking cycle. Epilepsia, (Amsterdam), 3, 69.

JASPER, H. H. and AJMONE-MARSAN, C. (1954). A stereotaxic atlas of the diencephalon of the cat. National Research Council of Canada, Ottawa.

JOUVET, M. (1965). Etude de la dualité des états de sommeil et des mécanismes de la phase paradoxale. In: M. Jouvet (Ed.), Aspects anatomofonctionnels de la physiologie du sommeil. Centre National de la Recherche Scientifique., (Paris), 397-449.

KIKUCHI, S. (1969). An electroencephalographic study of nocturnal sleep in temporal lobe epilepsy. Folia Psychiatrica et Neurologica Japonica, 23, 59-81.

KILLAM, K. F., KILLAM, E. K. and NAQUET, R. (1967). An animal model of light sensitive epilepsy. Electroencephalography and clinical Neurophysiology, 22, 497-513.

LAIRY-BOUNES, G. C., PARMA, M. and ZANCHETTI, A. (1952). Modifications pendant la réaction d'arrêt de Berger de l'activité convulsive produite par l'application locale de strychnine sur le cortex cérébral du lapin. Electroencephalography and clinical Neurophysiology, 4, 495-502.

LANGE, H., TANAKA, T. and NAQUET, R. (submitted for publication). Temporospatial display of subcortical spike activity in kindling epilepsy.

LANOIR, J. (1972). Etude électrocorticographique de la veille et du sommeil chez le chat. Thèse, Aix Marseille.

MAYANAGI, Y. and WALKER. A. E. (1974). Experimental temporal lobe epilepsy. Brain, 97, 423-446.

McINTYRE, D. C. and GODDARD, G. V. (1973). Transfer, interference and spontaneous recovery of convulsion kindled from the rat amygdala. Electroencephalography and clinical Neurophysiology, 35, 533-543.

MORRELL, F. (1973). Goddard's kindling phenomenon: a new model of the "mirror focus". In: H. C. Sabelli (Ed.), Chemical Modulation of Brain Function, Raven Press, New York, 207-223.

NAQUET, R. (1973). L'épilepsie photosensible du Papio papio. Un modèle de l'épilepsie photosensible de l'homme. Archives Italiennes de Biologie, 3, 516-526.

NAQUET, R. (1975). Genetic study of epilepsy: contributions of different models, especially the photosensitive Papio papio. In: M. A. Brazier (Ed.), Growth and development of the brain, 219-230. Raven Press, New York.

NAQUET, R., DROSSOPOULO, G. and SALAMON, G. (1956). Etude experimentale des effets de certains convulsivants: leurs relations avec l'excitabilité du système réticulaire, Revue Neurologique, $95,484-490$.
OLIVERAS, J. L., BESSON, J. M., GUILBAUD, G. and LEIBESKIND, J. C. (1974). Behavioral and electrophysiological evidence of pain inhibition from midbrain stimulation in the cat. Experimental Brain Research, 20, 32-44.

PASSOUANT, P., CADILHAC, J. and DELANGE, M. (1965). Indications apportées par l'étude du sommeil de nuit sur la physiopathologie des épilepsies. International Journal of Neurology 5, 207-216.

PURPURA, D. P., PENRY, J. K., WOODBURY, D. M. and WALTER, R. (Eds.) (1972). Experimental models of epilepsy, Raven Press.

RACINE, R. (1972). Modification of seizure activity by electrical stimulation. 1 . Afterdischarge threshold. Electroencephalography and clinical Neurophysiology, 32, 269-279.

SNIDER, R. S. (1974). Cerebellar modifications of abnormal discharges in cerebral sensory and motor areas. In: The Cerebellum, Epilepsy and Behavior. Plenum Press, New York.

SNIDER, R. S. and NIEMER, W. T. (1961). A stereotaxic atlas of the cat brain. University of Chicago Press, Chicago, lll.

STERMANN, M. B., KNAUSS, T., LEHMANN, D. and CLEMENTE, C. D. (1965). Circadian sleep and waking patterns in the laboratory cat. Electroencephalography and clinical Neurophysiology, 19, 509-517.

TANAKA, A. (1972). Progressive changes of behavioral and electroencephalographic response to daily amygdaloid stimulation in rabbits. Fukuoka Acta Medica, 63, 152-164.

TANAKA, T. and LANGE, $H$. (1975). L'effet d'embrasement (kindling effect) par stimulation aymgdalienne chez le chat et le rat. Revue Electroencephalographie et Neurophysiologie, 5, 41-44.

TANAKA, T, and NAQUET, R. (1975). Kindling effect and sleep organization in cats. Electroencephalography and clinical Neurophysiology, (in press).

TESTA, G. and GLOOR, P. (1974). Generalized penicillin epilepsy in the cat: effect of midbrain cooling. Electroencephalography and clinical Neurophysiology, 36, 517-524.

WADA, J. A. (1974). Progressive seizure recruitment in subhuman primates and effect of cerebellar stimulation upon developed vs. developing amygdaloid seizures. Commemorative Congress of the 10th Anniversary of the National Institute of Neurology, Mexico City, 3-8 Nov.

WADA, J. A. and OSAWA, T. (1974). Recurrent spontaneous generalized convulsion state induced by daily amygdaloid stimulation in Senegalese baboon, Papio papio. Annual Meeting of American Electroencephalographic Society, July 25 , Seattle.

WADA, J. A. and SATO, M. (1974). Generalized convulsive seizures induced by daily electrical stimulation of the amygdala in cats. Neurology, (Minneapolis), 24, (6), 565-574. 